\title{
Developmental Homeostasis of Mouse Retinocollicular Synapses
}

\author{
Anand R. Chandrasekaran, ${ }^{1 \star}$ Ruchir D. Shah, ${ }^{1 \star}$ and Michael C. Crair ${ }^{1,2}$ \\ ${ }^{1}$ Department of Neuroscience, Baylor College of Medicine, Houston, Texas 77030, and 2Department of Neurobiology, Yale University School of Medicine, \\ New Haven, Connecticut 06510
}

Spontaneous retinal waves during development are thought to provide an instructive signal for precise retinotopic mapping by correlating the activity of neighboring retinal ganglion cells. In mutant mice $\left(\beta 2^{-I-}\right)$ that lack correlated waves, retinocollicular map refinement is impaired. In vivo recordings reveal that neurons in the superior colliculus of $\beta 2^{-1-}$ mice have large receptive fields and low peak visual responses, resulting in a conservation of total integrated response. We find that this "response homeostasis" is maintained on a cell-bycell basis, and argue that it does not depend on regulation from the visual cortex during adulthood. Instead, in vitro recordings show that homeostasis arises from the conservation of total synaptic input from the retina, and that it is maintained via different mechanisms over development. In the absence of correlated retinal waves, $\beta 2^{-I-}$ neurons sample a larger number of weaker retinal inputs relative to controls after the first postnatal week. Once retinal waves are restored, developmental learning rules and homeostasis drive refinement so that fewer, stronger synapses are retained, as in wild-type mice, but from a larger retinal area. Homeostasis in neurons has been shown previously to regulate the gain of synaptic transmission in response to perturbations of activity. Our results suggest that during the development of sensory maps, a unique consequence of homeostatic mechanisms is the precise shaping of neuronal receptive fields in conjunction with activity-dependent competition.

Key words: retinal waves; superior colliculus; activity-dependent; homeostasis; development; mouse

\section{Introduction}

Vertebrate retinal ganglion cell (RGC) axons project to the brain in a stereotyped manner that preserves neighborhood relationships, resulting in topographic maps of visual space in central targets such as the superior colliculus and lateral geniculate nucleus (McLaughlin and O'Leary, 2005). The refinement of RGC axon projections from an initially coarse arrangement to their precise, topographically appropriate target zones occurs via a process of activity-dependent competition that is thought to follow Hebbian learning rules at the synapse (Constantine-Paton et al., 1990; Katz and Shatz, 1996; Zhang and Poo, 2001). This refinement depends on spontaneous waves of action potentials that sweep across the developing retina (McLaughlin et al., 2003; Chandrasekaran et al., 2005; Mrsic-Flogel et al., 2005). These retinal waves produce highly correlated activity among neighboring RGCs (Meister et al., 1991; Torborg and Feller, 2005), thereby providing the instructive signal necessary for retinotopic map refinement in target structures. In mice that lack the $\beta 2$ subunit

Received 0ct. 7, 2006; revised Jan. 4, 2007; accepted Jan. 8, 2007.

This work was supported by National Institutes of Health Grants R01 MH62639, R01 EY015788, and T32 EY07001. We gratefully acknowledge John Maunsell, Bill Bosking, and members of the Crair laboratory for helpful discussions and comments on this manuscript.

${ }^{*}$ A.R.C. and R.D.S. contributed equally to this work.

Correspondence should be addressed to Michael C. Crair, Department of Neurobiology, Yale University School of Medicine, P.0. Box 208001, New Haven, CT 06520-8001. E-mail: michael.crair@yale.edu.

DOI:10.1523/JNEUROSCI.4383-06.2007

Copyright $\odot 2007$ Society for Neuroscience $\quad 0270-6474 / 07 / 271746-10 \$ 15.00 / 0$ of the nicotinic acetylcholine receptor $\left(\beta 2^{-/-}\right.$mice $)$, spontaneous retinal waves are absent during the first postnatal week (Bansal et al., 2000). As a result of disrupting this instructive signal, anatomical refinement of the retinotopic map in the superior colliculus (SC) is perturbed in $\beta 2^{-/-}$animals (McLaughlin et al., 2003; Chandrasekaran et al., 2005).

To determine the functional consequences of this anatomical impairment, we previously examined receptive field (RF) properties of SC neurons in vivo (Chandrasekaran et al., 2005). Consistent with the anatomical phenotype, we found that RF areas were, on average, much larger in $\beta 2^{-/-}$mice. Interestingly, the peak visual response to small stimuli was also much weaker, and the decrease in peak response compensated for the increase in RF area such that the total visual response (defined as the sum of responses across the entire RF) remained constant between genotypes. We report here that the compensatory relationship between RF area and peak response holds true on a cell-by-cell basis, and we refer to this phenomenon as "response homeostasis".

The aim of this study is to examine how response homeostasis is implemented in the SC. Theoretically, response homeostasis could be achieved via the regulation of intrinsic neuronal excitability, by modulating the number and strength of synaptic inputs, or it could be a feature of the neural circuit. Here, we consider and test two specific hypotheses: that response homeostasis is maintained via modulation from the visual cortex, or that it is achieved by regulating the total synaptic input from the retina. In vivo physiological analysis reveals that input from the visual cor- 
tex is not required for maintaining response homeostasis. Instead, our in vitro physiology demonstrates that it is the number and strength of retinal inputs that is preserved in $\beta 2^{-/-}$animals, which is sufficient to explain response homeostasis in young adult SC neurons. Furthermore, we establish that the total synaptic input from the retina feeding into SC neurons is conserved over development regardless of the level of maturity of the retinocollicular synapse or the retinotopic map. These results suggest that homeostatic mechanisms in the SC are coordinated with developmental learning rules to maintain stable responses to retinal ganglion cell afferent activity.

\section{Materials and Methods}

Mice lacking the $\beta 2$ subunit of nicotinic acetylcholine receptors $\left(\beta 2^{-/-}\right.$ mice) were generated in the Beaudet laboratory at Baylor College of Medicine (Houston, TX) and back-crossed at least six generations onto the C57BL/6 background. Genotypes were determined by genomic PCR using primer sequences and amplification parameters described by $\mathrm{Xu}$ et al. (1999). All experiments were performed blind to genotype; control mice were wild-type (WT) and heterozygous littermates of $\beta 2^{-1-}$ mice. Animals were treated in accordance with Institutional Animal Care and Use Committee and Baylor College of Medicine guidelines. All data values are presented in the text as mean \pm SEM, and differences in means were tested for significance using a Student's $t$ test, unless otherwise indicated.

In vivo physiology. Mice aged 1-2 months were anesthetized using urethane $(1.0 \mathrm{~g} / \mathrm{kg}$, i.p.), and were also injected with atropine $(5 \mathrm{mg} / \mathrm{kg})$ and dexamethasone $(0.2 \mathrm{mg} /$ mouse) as described previously (Kalatsky and Stryker, 2003). Mice were then placed in a stereotaxic apparatus with a modified gas mask that allowed unobstructed view of visual space and provided additional stability with an incorporated bite bar. Anesthetic was supplemented by $0.5-1 \%$ isoflurane in a mixture of oxygen and nitrous oxide (3:2). The animal's temperature was monitored and used to control a thermal pad placed under it (Harvard Apparatus, Holliston, MA). The heart rate was monitored throughout the experiment to verify the health of the animal. A craniotomy $\left(\sim 4 \mathrm{~mm}^{2}\right)$ was performed to expose the cortex overlying the colliculus. A tungsten microelectrode (1-5 MÙ; FHC, Bowdoinham, ME) was lowered into the brain using a micromanipulator (Newport, Irvine, CA). The responses obtained were amplified and filtered (10000×; 0.3-5 kHz; A-M Systems, Sequim, WA) and digitized onto a computer $(25 \mathrm{kHz}$; National Instruments, Austin, TX). Stimuli were controlled using a VSG 2/3 card (Cambridge Research Systems, Kent, England) and presented on a monochrome monitor (Vision Research Graphics, Durham, NH).

Receptive field reconstruction and analysis. RFs were reconstructed using small $\left(4-10^{\circ}\right)$ square light stimuli presented for $300 \mathrm{~ms}\left(7-12 \mathrm{~cd} / \mathrm{m}^{2}\right)$ on a dim background $\left(0.5-1 \mathrm{~cd} / \mathrm{m}^{2}\right)$ with $750-900 \mathrm{~ms}$ between stimuli, in pseudorandom order to form a grid in visual space. Stimuli were repeated 3-5 times per grid location. Stimulus size was chosen so that there were 5-6 stimuli across the width of the RF, yielding similar sampling densities between genotypes (control, $5.7 \pm 0.3$ stimuli/RF diameter; $\beta 2^{-/-}, 5.9 \pm 0.5$ stimuli/RF diameter; $p=0.63$ ). Spike waveforms were analyzed offline in Matlab (Mathworks, Natick, MA) and single units isolated using software window discriminators. Only units with visually separable waveforms were classified as isolated single neurons. The average spike counts in response to the squares of light for each grid location were used to reconstruct the neurons RF. The RF was then fit with an elliptical two-dimensional (2D) Gaussian (Tavazoie and Reid, 2000; Chandrasekaran et al., 2005). The quality of the Gaussian fit was examined using Pearson's regression coefficient $(r)$ between the raw data and the fit elliptical Gaussian. Only data from neurons with $r^{2}>0.5$ was considered a good fit and retained for additional analysis.

$$
g(x, y)=\left(V / 2 \pi \sigma_{x} \sigma_{y}\right) \exp \left(-x^{2} / 2 \sigma_{x}^{2}-y^{2} / 2 \sigma_{y}^{2}\right)
$$

Equation 1 describes the 2D Gaussian used to fit the RF without rotation for simplicity, where $g(0,0)$ is the peak response, $\pi \sigma_{x} \sigma_{y}$ is the area of the
RF, and $V$ corresponds to the volume under the curve, or the integrated total response of the cell.

$$
\log (g(0,0))=-\log \left(\pi \sigma_{x} \sigma_{y}\right)+\log (V / 2)
$$

If the total response $(V)$ of the cell is a constant across the population of neurons, as shown in Equation 2, a plot of $\log (g(0,0))$ versus $\log \left(\pi \sigma_{x} \sigma_{y}\right)$ should be a straight line with slope -1 and $y$-intercept of $\log (V / 2)$. This relationship is shown as a scatter plot in Figure $1 F$, with $\log ($ peak response) versus $\log$ (area) [e.g., $\log \left(g(0,0)\right.$ vs $\left.\log \left(\pi \sigma_{x} \sigma_{y}\right)\right]$ plotted for each neuron.

Size tuning. To obtain size-tuning curves, the RF center calculated by reverse correlation was used to present circles of varying diameter in pseudorandom order. Each stimulus diameter was presented 10 times to obtain an averaged response. Cortical lesions were performed using a surgical cautery device (General Medical, Richmond, VA) under constant irrigation. Lesions encompassed a region from bregma -5 to -2 $\mathrm{mm}$ of the ipsilateral cortex that includes area V1. An example of a lesioned cortex is shown in supplemental Figure 1 (available at www.jneurosci.org as supplemental material).

In vitro physiology. Parasagittal brain slices were prepared from postnatal day 6 (P6)-P7 and P21-P25 pups by mounting the brain at an angle of $10-15^{\circ}$ relative to the midline and making $350-400 \mu \mathrm{m}$ sections that preserved the optic tract and stratum griseum superficiale (SGS) layer of the superior colliculus. Slices were cut in ice-cold artificial CSF (ACSF) saturated in $95 \% \mathrm{O}_{2}$ and $5 \% \mathrm{CO}_{2}$ containing the following (in $\mathrm{mM}$ ): 124 $\mathrm{NaCl}, 5 \mathrm{KCl}, 1.25 \mathrm{NaH}_{2} \mathrm{PO}_{4}, 2 \mathrm{MgSO}_{4} 2 \mathrm{CaCl} 2,26 \mathrm{NaHCO} 3$, and 11 glucose, $\mathrm{pH} 7.2,290-310 \mathrm{mOsm}$. Slices were allowed to recover at room temperature in bubbled ACSF for at least $1 \mathrm{~h}$ before recording. Experiments were performed at room temperature with bubbled ACSF perfused at a rate of $2-3 \mathrm{ml} / \mathrm{min}$. Whole-cell recording electrodes $(2-5 \mathrm{M} \Omega$ ) contained the following (in $\mathrm{mm}$ ): 100 cesium gluconate, $17.5 \mathrm{CsCl}, 8$ $\mathrm{NaCl}, 10$ HEPES, 0.2 EGTA, $4 \mathrm{Mg}$-ATP, 0.3 GTP, 7 phosphocreatine, and 10 BAPTA, pH 7.2-7.5, 290-310 mOsm. Whole-cell voltage-clamp recordings were performed on cells in the SGS and were always monitored initially at a holding potential of $-70 \mathrm{mV}$. Stimuli $(30-400 \mu \mathrm{A})$ were delivered every $10 \mathrm{~s}$ through bipolar stainless steel stimulating electrodes (FHC) placed in the optic tract. Bath ACSF contained $10 \mu \mathrm{m}$ bicuculline (Tocris, Ellisville, MO) to eliminate inhibitory currents for all experiments. Responses were considered monosynaptic if they exhibited short and constant latency (3-5 ms) that did not change with stimulus intensity. Data was collected and analyzed using software written in IgorPro (WaveMetrics, Lake Oswego, OR). Input and series resistances were measured continuously to monitor the health of the cell, and data were discarded from analysis if these parameters drifted more that $20 \%$ over the course of the experiment. The mean input resistance measurements did not differ between genotypes at either P6 $-\mathrm{P} 7$ (control, $872 \pm 67 \mathrm{M} \Omega$; $\beta 2^{-1-}, 954 \pm 54 \mathrm{M} \Omega ; p=0.37$ ) or at P21-P25 (control, $722 \pm 54 \mathrm{M} \Omega$; $\beta 2^{-/-}, 649 \pm 59 \mathrm{M} \Omega ; p=0.40$ ). Only one cell per slice was used.

Minimal stimulation experiments. AMPAR responses were monitored at $-70 \mathrm{mV}$ holding potential, and were subsequently blocked using $10 \mu \mathrm{M}$ 1,2,3,4-tetrahydro-6-nitro-2,3-dioxo-benzo[f] quinoxaline-7sulfonamide (NBQX; Tocris). The cell was then switched to $+40 \mathrm{mV}$ holding potential and a stable NMDA receptor (NMDAR) response was recorded. Stimulation strength was then adjusted until a mixture of subthreshold (failures) and suprathreshold (successes) responses were observed. Stimulation strength was then increased in variable increments to recruit more inputs until a saturating current response was achieved. This slow increase in stimulation strength was performed to monitor the decay kinetics at each stimulation strength to ensure recruitment of monosynaptic inputs. Furthermore, fibers stimulated with extremely high currents sometimes died, and sequential recruitment also allowed observation of true saturating current level before possible axon degeneration. It should also be noted that because of polysynaptic circuitry in our slice preparation, these estimates were not made using AMPAR current responses, as the saturating response was often caused by polysynaptic connections rather than monosynaptic retinal inputs. Addition of $10 \mu \mathrm{M}$ NBQX blocked these excitatory polysynaptic inputs. For analysis, the amplitudes measured at minimal stimulation strength were con- 
verted into amplitude frequency histograms, and successes were separated from failures using the bimodality in the distributions. If a clear bimodality was not observed, each sweep was examined individually to qualify the value as either a failure or success. The successes (single-fiber responses) determined from this analysis were then averaged, as were 10-20 sweeps measured at the saturating stimulation strength. The number of inputs was estimated as the mean saturating responses divided by the mean single fiber response.

Strontium evoked AMPA miniature events. Stable whole-cell voltageclamp recordings were established at $-70 \mathrm{mV}$ holding potential, and extracellular $\mathrm{Ca}^{2+}$ in the bath ACSF was replaced with $3 \mathrm{~mm} \mathrm{Sr}{ }^{2+} . \mathrm{Sr}^{2+}$ desynchronizes vesicle release, allowing evoked miniature currents events to be analyzed (Goda and Stevens, 1994; Xu-Friedman and Regehr, 1999; Lu et al., 2006). Evoked miniature events were recorded in $1 \mathrm{~s}$ epochs every $5-10 \mathrm{~s}$ in IgorPro, and subsequently imported into Mini Analysis software (Synaptosoft, Decatur, GA). Amplitude thresholds were set at 2.5 times root mean square noise, and at least 100 events were used for analysis in each cell. Root mean square noise amplitudes did not differ between genotypes at either P6-P7 (control, $1.74 \pm .07 \mathrm{pA} ; \beta 2^{-/-}$, $1.73 \pm .08 \mathrm{pA} ; p=0.94$ ) or at P21-P25 (control, $1.73 \pm .18 \mathrm{pA} ; \beta 2^{-/-}$, $1.84 \pm .22 \mathrm{pA} ; p=0.73$ ). Amplitude-frequency histograms were created using $1 \mathrm{pA}$ bins and were normalized to the number of events in each experiment. Cumulative probability distributions were also plotted in 1 pA bins.

AMPA/NMDA ratios. Stable monosynaptic AMPA responses were recorded at $-70 \mathrm{mV}$ holding potential (bath contained $2 \mathrm{mM} \mathrm{Mg}^{2+}$ and 10 $\mu \mathrm{m}$ bicuculline). AMPA receptors were then completely blocked with 10 $\mu \mathrm{M}$ NBQX, and the holding potential was switched to $+40 \mathrm{mV}$ holding potential to record NMDA receptor-mediated currents at the same stimulation strength. The amplitudes of the peak currents were measured for each stimulus, and AMPA/NMDA ratios were computed by taking the average of 20 sweeps at each holding potential.

\section{Results}

Collicular response homeostasis is maintained on a

cell-by-cell basis in vivo

We reported previously that refinement of retinocollicular projections is impaired in mutant mice $\left(\beta 2^{-/-}\right)$that lack retinal waves during the first week after birth (Chandrasekaran et al., 2005). This causes, on average, enlarged SC neuron RFs in $\beta 2^{-/-}$ mice compared with control mice (Fig. 1C) (control, $105 \pm 11$ $\operatorname{deg}^{2}, n=43$ cells; $\beta 2^{-/-}, 456 \pm 89 \mathrm{deg}^{2}, n=19$ cells; $p \ll$ $0.001)$. Interestingly, the peak response of collicular neurons to visual stimuli is also much lower in $\beta 2^{-/-}$animals (Fig. $1 D$ ) (control, $35.2 \pm 3.3 ; \beta 2^{-/-}, 8.8 \pm 1.1$ spikes per stimulus; $p \ll$ $0.001)$. The decrease in peak response in $\beta 2^{-/-}$neurons compensates for the increase in RF area so that the total response, defined as the volume under the Gaussian best fit to the RF (see Materials and Methods), is the same across genotypes (Fig. 1E) (control, $5520 \pm 340 ; \beta 2^{-/-}, 5620 \pm 890$ spikes $\left./ \mathrm{deg}^{2} ; p=0.9\right)$. Because the product of RF area and peak response is proportional to the total response, a plot of the logarithm of these measures should result in a linear relationship of slope -1 if the total response is constant across individual neurons (Eq. 2). Figure $1 F$ depicts such a plot, and indeed a line of slope -1 is a good fit for control as well as $\beta 2^{-1-}$ neurons (control, $r^{2}=0.59$ for the correlation between real and fit data for the peak response; $\beta 2^{-/-}, r^{2}=0.52$; combined, $\left.r^{2}=0.79\right)$. The existence of this relationship on a cell-by-cell basis suggests that there is a cellular mechanism in place that regulates neuronal response as a function of RF size.

We first examined whether regulation of the number and strength of retinal inputs onto SC neurons could explain response homeostasis. For example, response homeostasis in $\beta 2^{-/-}$SC neurons relative to controls could emerge by sampling a similar number of retinal inputs with equal synaptic weights, but from a larger retinal area (Fig. $1 G$, middle). Alternatively,
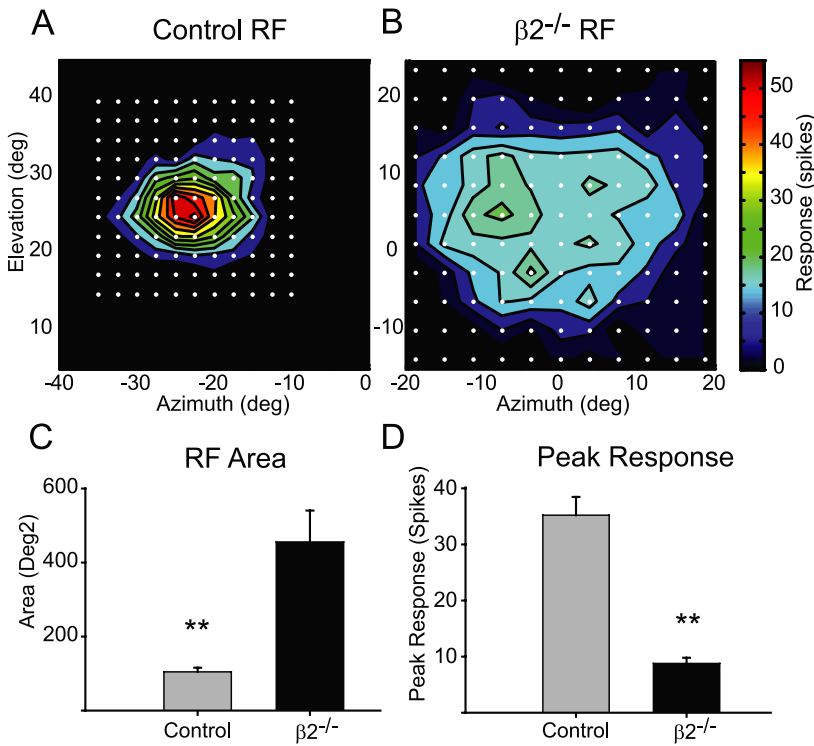

Peak Response

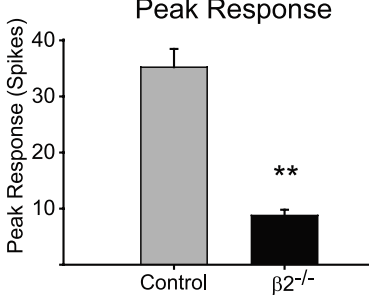

E

Total Response

$\mathrm{F}$
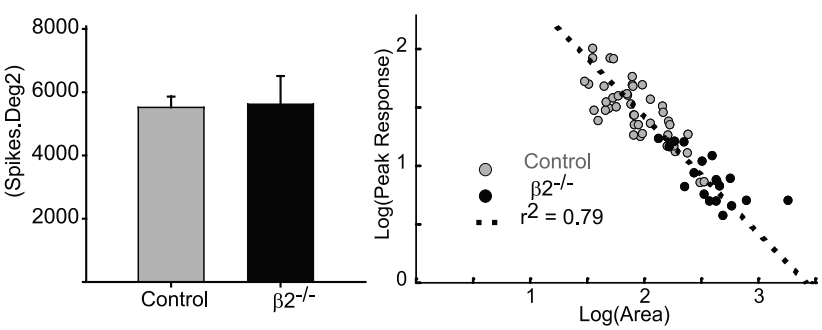

G

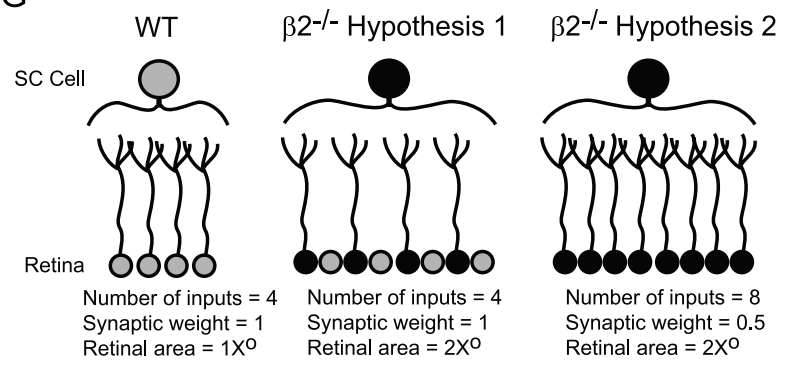

Figure 1. Response homeostasis is maintained on a cell-by-cell basis in vivo. $A$, Example RF of an isolated neuron in the $\mathrm{SC}$ of a young-adult control mouse. White dots correspond to stimulation sites. Stimuli consisted of squares of light formed from the vertices of the dots surrounding the central dot. $B$, Example RF in a young-adult $\beta 2^{-1-}$ mouse. Color bar corresponds to response strength (spikes per stimulus) and is common to both examples. $C$, Quantification of $R F$ area reveals significantly larger average RF sizes in $\beta 2^{-/-}$mice (C-F; gray, control, $n=43$; black, $\left.\beta 2^{-/-}, n=19\right)$. D, Mean peak response of neurons in $\beta 2^{-/-}$mice is significantly lower than control mice. $\boldsymbol{E}$, The average total response across the population of neurons is not different in the two genotypes $(p=0.9)$. $\boldsymbol{F}$, Scatter plot of peak response versus area in the log domain on a cell-by-cell basis. Both control and $\beta 2^{-/-}$ neuron responses are fit well by a line of slope -1 , demonstrating that, in each cell, RF area and response are precisely coordinated (control as gray circles, $r^{2}=0.59 ; \beta 2^{-1-}$ as black circles, $r^{2}=$ 0.52 ). After combining all cells across genotypes, the population enjoys a better fit to a line of slope -1 (dashed line; $r^{2}=0.79$ ). Best-fit lines for the individual genotypes were removed as they overlapped with the population fit (error bars indicate SEM; ${ }^{* *} p \ll 0.001$ ). G, Diagram depicting two hypotheses for how $\beta 2^{-/-}$SC neurons could maintain response homeostasis. Relative to control neurons, $\beta 2^{-/-}$neurons could have either the same number of similar strength inputs distributed over a larger retinal area (Hypothesis 1 ) or a larger number of weaker inputs over a similarly large retina area (Hypothesis 2).

$\beta 2^{-/-}$neurons could sample a larger number of weaker strength retinal inputs from a larger retinal area (Fig. $1 G$, right). Both hypotheses would preserve total synaptic input and result in lower peak responses and larger RF areas. To distinguish between 
A

Control Amplitude Plots

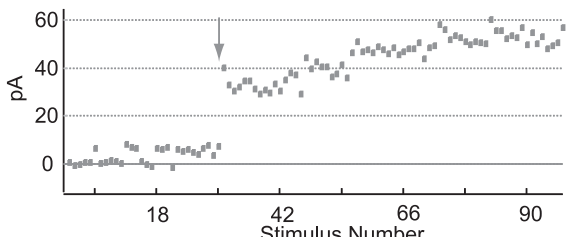

C

Control SF and Saturating Responses

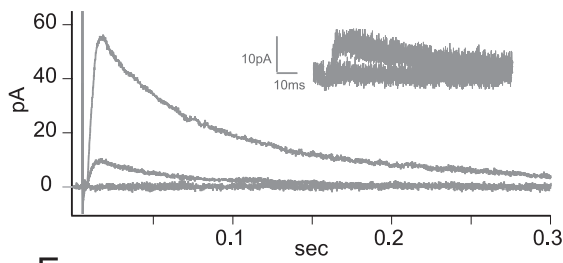

E

NMDA Single Fiber Amplitude P21-25

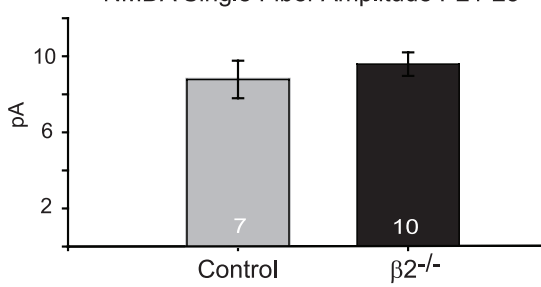

B

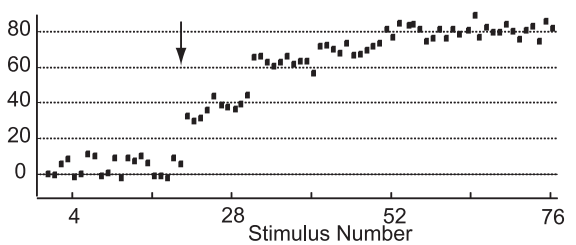

D
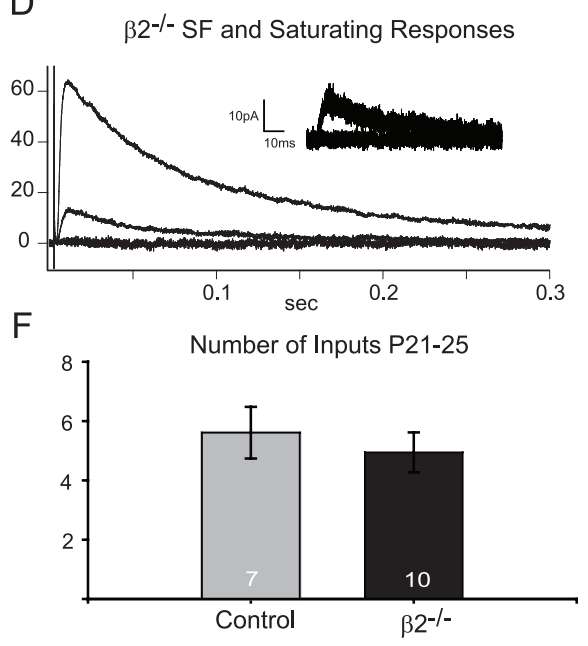

Figure 2. $\quad \beta 2^{-1-}$ neurons sample a number of retinal inputs similar to control cells at P21-P25. $\boldsymbol{A}, \boldsymbol{B}$, Example minimal stimulation experiments for a control $(\boldsymbol{A})$ and $\beta 2^{-/-}(\boldsymbol{B})$ cell, with peak amplitudes of NMDA currents plotted as a function of stimulus number over the course of the experiment. Stimuli delivered before the arrow were at minimal stimulation intensity and evoked a mixture of failures and successes. Stimuli delivered after the arrow were steadily increased in intensity until a saturating response was achieved. $\boldsymbol{C}$, Example traces of failures, single fiber responses, and saturating responses (average of five sweeps each) from a control animal. Inset depicts five failures and five successes evoked at minimal stimulation strength overlaid on top of each other from the same experiment. $\boldsymbol{D}$, Example traces for a $\beta 2^{-/-}$animal, as described in $\boldsymbol{C}$. $\boldsymbol{E}$, Mean NMDA single-fiber amplitudes (quantified as described in Materials and Methods) in P21-P25 $\beta 2^{-/-}$and control animals are similar (control, $n=$ $\left.7 ; \beta 2^{-1-}, n=10 ; p=0.5\right) . F$, Summary of estimated number of inputs across P21-P25 control and $\beta 2^{-/-}$animals reveals no statistical difference (control, $n=7 ; \beta 2^{-\prime-}, n=10 ; p=0.6$ ).

these two possibilities, we used an in vitro slice preparation to stimulate RGC axons in the optic tract and performed whole-cell voltage-clamp recordings from cells in the superficial layers (SGS) of the SC in young adult mice aged P21-P25.

\section{Number of retinal inputs is similar in $\beta 2^{-/-}$and control mice at P21-P25}

To measure the number of retinal inputs converging onto an SC cell, we used a "minimal stimulation" paradigm that allows us to isolate responses to single retinal ganglion cell fibers. In wholecell voltage-clamp mode, we first isolated NMDAR mediated responses in $10 \mu \mathrm{M}$ NBQX and $10 \mu \mathrm{M}$ bicuculline at a holding potential of $+40 \mathrm{mV}$. After a stable baseline was recorded, we lowered the stimulus intensity until a mixture of failures and successes was achieved (Fig. $2 A, B$ ). The NMDA single fiber amplitude is the average amplitude of successful responses to minimal stimulation (Fig. 2C,D, insets, $E$ ). We then slowly increased the stimulation strength to recruit more retinal inputs until a saturating response level was reached (Fig. $2 A, B$ ). The size of the step increases is variable; the purpose is not to observe the number of steps in the amplitude distributions, but simply to ensure recruitment of monosynaptic inputs until saturation is achieved (see Materials and Methods). To estimate the number of inputs, we divided the mean saturating response by the mean single fiber response for each neuron. This analysis makes two important assumptions. First, that the number of release sites per input is the same (each input contributes equally to the response), and second, that the number of retinal inputs that can be activated in our slice preparation is similar, on average, across animals. Given these assumptions, we estimate that the NMDA single fiber amplitude (Fig. 2E) (control, $\left.8.8 \pm 1.0 ; \beta 2^{-1-}, 9.6 \pm 0.6 \mathrm{pA} ; p=0.5\right)$ and the number of converging retinal inputs is the same in $\beta 2^{-1-}$ mice and littermate controls at P21-P25 (Fig. $2 F$ ) (control, $\left.5.5 \pm 0.9 ; \beta 2^{-/-}, 5.0 \pm 0.7 ; p=0.6\right)$, despite their dramatically different RF areas.

\section{Retinocollicular synaptic strength is similar in $\beta 2^{-/}$and control mice at P21-P25}

At resting membrane potentials, glutamatergic synaptic transmission occurs primarily through AMPA receptors (AMPARs), and the experience-dependent strengthening and weakening of these synapses in numerous brain areas is known to involve trafficking of AMPARs to or away from new or existing synapses (Malinow and Malenka, 2002). To examine the synaptic weight of retinal inputs to collicular neurons at P21-P25, we first measured the amplitude of AMPAR-mediated miniature synaptic events. To do so, we initially evoked reliable AMPAR responses at -70 $\mathrm{mV}$ holding potential, and then replaced extracellular calcium with strontium (Fig. $3 A, B)$. Strontium desynchronizes presynaptic vesicular release in response to action potentials so that postsynaptic responses are composed of events at single synapses, or "evoked miniature events" (Goda and Stevens, 1994; Xu-Friedman and Regehr, 1999). The averaged amplitude histograms of all such evoked miniature events in $\beta 2^{-1-}$ mice $(n=5)$ and littermate controls $(n=5)$ are very similar (Fig. $3 C)$, and the corresponding cumulative probability distributions were also overlapping (Fig. 3D). No difference in their means was detected between genotypes (Fig. $3 D$, inset) (control, $10.0 \pm 0.5 ; \beta 2^{-/-}, 9.6 \pm 0.5 \mathrm{pA} ; p=$ $0.6)$. These measurements compare synaptic weights at single inputs (single-fiber NMDA amplitudes) and single synapses (evoked AMPA minis). Because they do not differ between genotypes, these results predict that the ratio of AMPA to NMDA currents measured across a population of inputs and synapses should be similar in $\beta 2^{-1-}$ mice and littermate controls. We therefore measured these ratios, as shown in Figure $3 E, F$. AMPAR-mediated currents were isolated at $-70 \mathrm{mV}$ holding potential, and NMDAR-mediated currents were isolated in 10 $\mu \mathrm{M}$ NBQX at $+40 \mathrm{mV}$ holding potential. By comparing the ratio of the peak currents at their respective holding potentials, we computed AMPA/NMDA ratios for each collicular neuron. The mean AMPA/NMDA ratio shows no significant difference between genotypes (Fig. 3F, inset) (control, $1.6 \pm 0.2 ; \beta 2^{-/-}, 1.8 \pm$ $0.2 ; p=0.6$ ), confirming the prediction and providing additional evidence that the strength of retinal inputs are similar in $\beta 2^{-/-}$ and control mice at P21-P25. 
Homeostasis of retinal synaptic input is maintained early in development

At the end of the $\beta 2$-acetylcholine receptor-mediated wave epoch $(\sim \mathrm{P} 8$ in $\beta 2^{-1-}$ mice), retinocollicular projection zones are at their largest in $\beta 2^{-/-}$mice and then partially refine over the next several weeks (Chandrasekaran et al., 2005). For technical reasons, we cannot map visual RF fields this early in development, but the spread of RGC projections suggests that RFs of single SC cells would be larger at P7 than at P21. To probe whether similar synaptic and circuit mechanisms exist early in development to maintain constant retinal input in $\beta 2^{-/-}$mice with large target zones, we repeated the in vitro experiments described above for P21-P25 animals in P6-P7 mice. We first estimated the number of retinal inputs using our minimal stimulation paradigm (Fig. $4 A, B$ ). Although NMDA single fiber amplitudes are similar in $\beta 2^{-/-}$mice and littermate controls at P6-P7 (Fig. 4C) (control, $7.4 \pm$ $\left.1.1 ; \beta 2^{-/-}, 8.5 \pm 1.0 \mathrm{pA} ; p=0.5\right)$, the saturating response was much larger on average in $\beta 2^{-/-}$mice, yielding a significantly higher estimate of the number of functional retinal inputs (Fig. 4D) (control, $\left.5.2 \pm 0.4 ; \beta 2^{-/-}, 8.7 \pm 0.9 ; p<0.05\right)$. To determine whether the larger number of retinal inputs in $\beta 2^{-/-}$mice was compensated for by a decrease in synaptic strength, as is expected with response homeostasis, we measured the amplitudes of strontium-evoked AMPA miniature events at P6-P7 (Fig. 5A,B). We observed many more large-amplitude AMPAminiature events in control mice than in the $\beta 2^{-/-}$neurons (Fig. $5 C$ ). Consistent with this, the cumulative probability distribution for $\beta 2^{-/-}$minis was shifted toward lower values relative to control events (Fig. 5D). This results in a lower mean of $\beta 2^{-1-}$ evoked AMPA-mini amplitudes than control mice (Fig. 5D, inset) (control, $10.0 \pm 0.6 ; \beta 2^{-/-}, 7.8 \pm 0.5 \mathrm{pA} ; p<0.05$ ). We also found that AMPA/NMDA ratios were significantly lower in $\beta 2^{-1-}$ mice compared with littermate controls at P6-P7 (Fig. 5F, inset) (control, $0.8 \pm 0.1 ; \beta 2^{-/-}, 0.4 \pm 0.1 ; p<0.01$ ). These results suggest that response homeostasis in $\beta 2^{-/-}$SC neurons is maintained at an early, unrefined age by sampling a larger number of weaker strength retinal inputs.

\section{Visual cortex modulates collicular}

\section{RFs, but is not required to maintain homeostasis}

The visual cortex is another major source of synaptic input onto visually responsive SC cells. To determine whether modulation from the visual cortex contributes to response homeostasis, we examined isolated collicular neuron RFs before and after ablating the ipsilateral visual cortex. These in vivo experiments were performed by first mapping SC neuron RFs and then presenting a set of variable diameter circular stimuli centered on the RF centers.
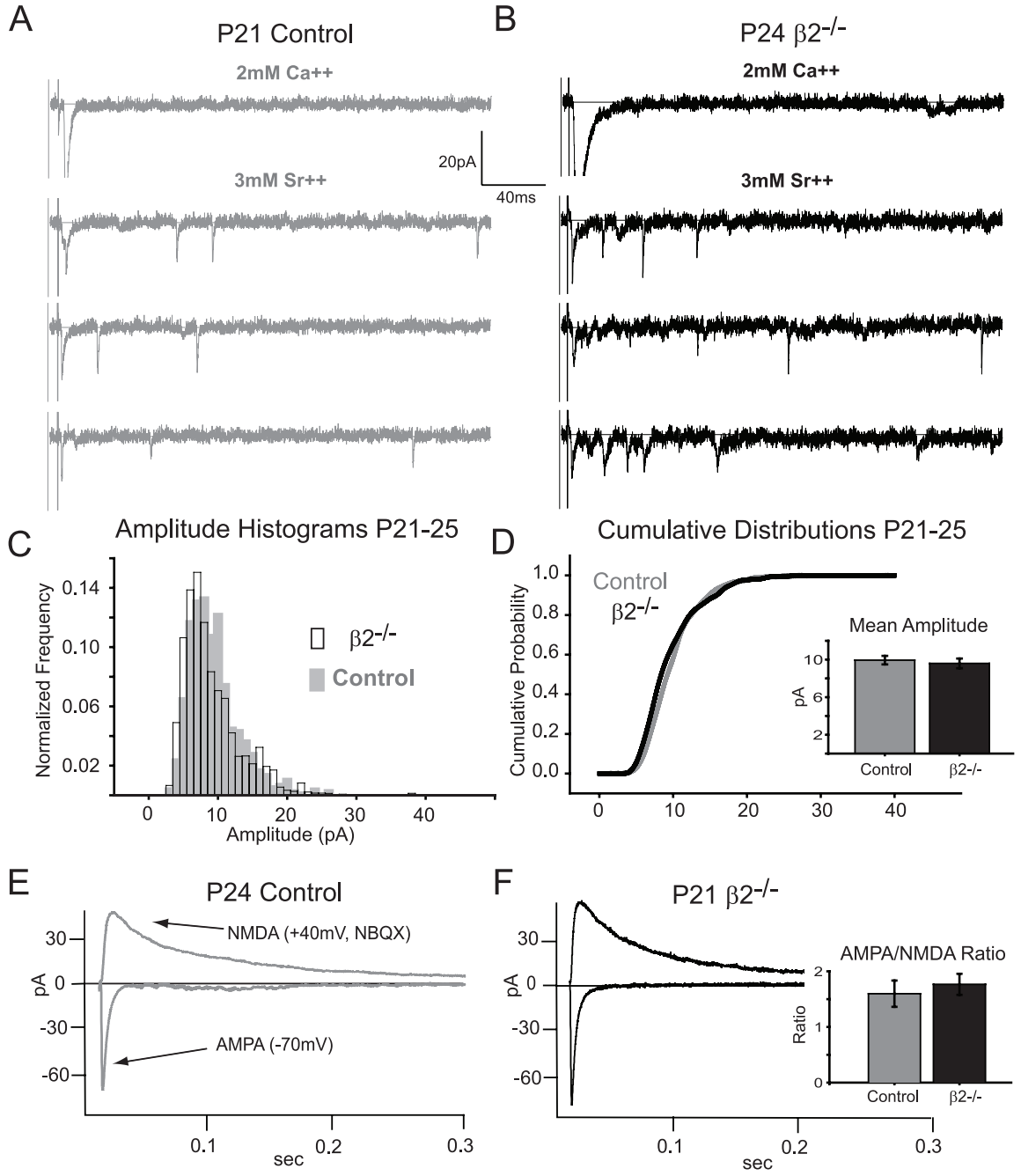

Figure 3. Synaptic strength at P21-P25 is similar between $\beta 2^{-/-}$and controls. $A$, Example strontium-evoked AMPA miniature experiments in a neuron from a P21 control animal. The top trace shows synchronous AMPAR current evoked in $2 \mathrm{~mm} \mathrm{Ca}^{2+}$ at $-70 \mathrm{mV}$ holding potential. The bottom three traces show examples of desynchronized AMPA miniature events evoked after eplacing extracellular $\mathrm{Ca}^{2+}$ with $3 \mathrm{~mm} \mathrm{Sr}{ }^{2+}$. B, Same as in $A$, but for a neuron from a P24 $\beta 2^{-1}$ animal. The scale bar is the same for all traces. $C$, Averaged amplitude histograms of all evoked AMPA miniature events in control (gray-filled, $n=5$ ) and $\beta 2^{-/-}$(open bars, $n=5$ ) cells. $\boldsymbol{D}$, Mean cumulative probability distributions for control cells (gray) and $\beta 2^{-/-}$cells (black) genotypes ( $p=0.6)$. $\boldsymbol{E}$, Example AMPA/NMDA ratio experiment showing isolated AMPA and NMDA receptor-mediated currents in a neuron from a P24 control animal. $\boldsymbol{F}$, Same as for $\boldsymbol{E}$, but for a neuron from a P21 $\beta 2^{-\prime-}$ animal. Inset depicting summary of mean AMPA/NMDA ratios in control (gray, $n=7)$ and $\beta 2^{-/-}($black, $n=9$ ) mice reveals similar values $(p=0.6)$.

These stimuli were used to construct response-diameter (sizetuning) plots for each isolated neuron before and after visual cortex lesions (Fig. 6A, B). Because the only major inputs active in the postlesion condition are retinal inputs, and the tuning curves remain broad in the $\beta 2^{-/-}$mice, these measurements reveal that a much larger retinal area contributes directly to the receptive field of SC neurons in $\beta 2^{-1-}$ mice compared with controls. The peak of the size-tuning plot occurs at smaller stimulus sizes in controls than $\beta 2^{-/-}$mice, as expected. However, the shape of the size-tuning curves is not greatly affected by the visual cortex lesion.

We also examined the size-tuning curves after normalizing the stimulus diameter by the RF area on a cell-by-cell basis. After normalizing by RF area, the size tuning curves in both control and $\beta 2^{-1-}$ neurons (supplemental Fig. 2, available at www. jneurosci.org as supplemental material) rise steeply and reach similar peak amplitudes at less than one receptive field diameter, 
A

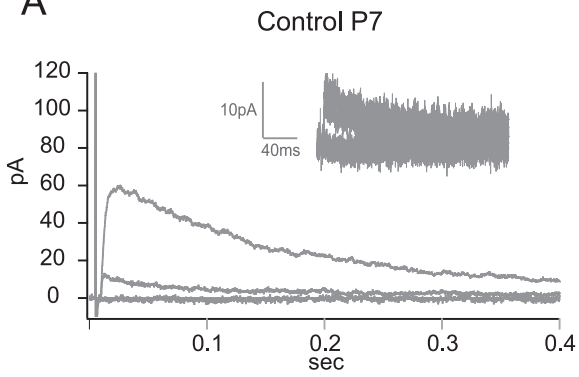

C

NMDA Single Fiber Amplitude P6-7

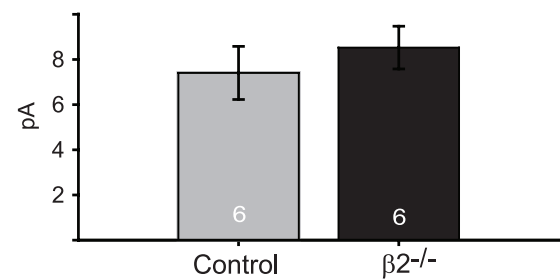

B

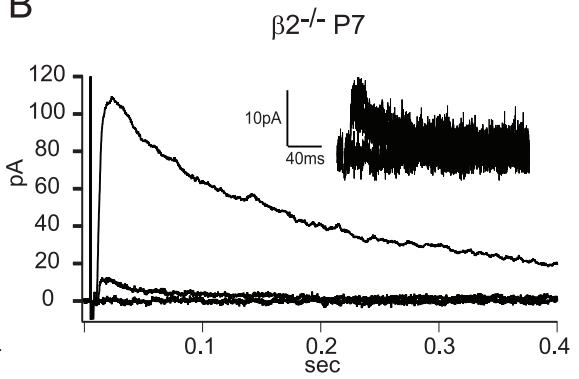

D

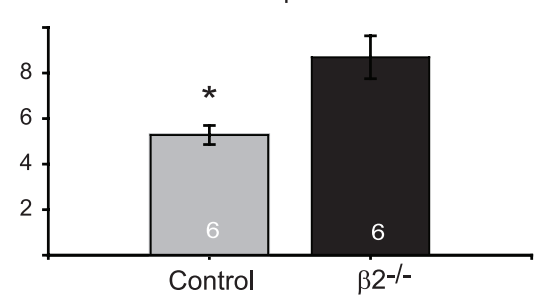

Figure 4. $\quad B 2^{-1-}$ neurons sample a larger number of retinal inputs than controls at $P 6-P 7 . A, B$, Example minimal stimulation experiments for a control (gray) and $\beta 2^{-1-}$ (black) cell at P7, as described in Figure 2, $C$ and $D$. Traces depict failures, single-fiber responses, and saturating responses (average of five sweeps each). Note larger saturating response in $\beta 2^{-/-}$ example. Insets show five failures and five successes at minimal stimulation intensity overlaid on top of each other. $C$, Mean NMDA single-fiber responses in control (gray, $n=6)$ and $\beta 2^{-/-}($black, $n=6)$ cells at P6-P7 are not different $(p=0.5)$. D, Estimated number of inputs at P6-P7 in control (gray, $n=6)$ and $\beta 2^{-1-}$ (black, $\left.n=6\right)$ neurons. Means were statistically higher in the $\beta 2^{-1-}$ group ( $\left.{ }^{*} p<0.05\right)$.

offering additional evidence that collicular neuron RFs are constructed in a similar manner, regardless of receptive field size. Comparison of the RF area and peak response before and after lesioning the visual cortex in control and $\beta 2^{-/-}$mice shows that the degree of RF modulation by the visual cortex is small relative to the difference in RFs in the two genotypes (Fig. 6C,D). Moreover, the modulation, in so far as it exists, obeys response homeostasis (Fig. 6E, F). The RF area and peak response show a small, but statistically significant change because of the lesion in control mice (Fig. $6 C, D)(p<0.01$ for RF area; $p<0.05$ for peak response), and a similar trend in the $\beta 2^{-1-}$ mice that does not reach statistical significance ( $p=0.18$ for RF area; $p=0.08$ for peak response) (data not shown). The total response, however, shows no difference statistically for each genotype prelesion and postlesion (control, $p=0.43 ; \beta 2^{-1-}, p=0.73$ ) or across the entire population of neurons prelesion and postlesion (Fig. $6 E$ ) ( $p=0.7$, two-way ANOVA), consistent with the hypothesis that cortical input is not required to maintain response homeostasis. We also examined the relationship between peak response and $\mathrm{RF}$ area on a cell-by-cell basis prelesion and postlesion (Fig. $6 F)$. Neuronal responses both before and after lesion enjoy a good fit with the best-fit line of slope -1 (prelesion, $r^{2}=0.80$ for the correlation between real and fit data for the peak response; postlesion, $r^{2}=0.73$ ).

The results of these visual cortex lesion experiments confirm that the amount of retinal area feeding into any given SC cell is larger in $\beta 2^{-/-}$mice, and suggest a limited role of the visual cortex in maintaining response homeostasis. This is not to say that the visual cortex has no role in shaping SC response properties. In fact, acute ablation of the ipsilateral visual cortex (Berman and Cynader, 1976; Rhoades and Chalupa, 1978a,b) decreases the incidence of directionally selective cells encountered in the superficial SC, but did not significantly alter the response properties of cells to spots of light of varying size (Rhoades and Chalupa, 1978a,b), consistent with our results.

\section{Discussion}

We showed previously that SC neurons in $\beta 2^{-/-}$mice have larger RFs and smaller peak responses so that, on average, the total visual response is similar to neurons in the control SC. In this study, we show that the relationship between RF area and peak response holds true on a cell-by-cell basis in both $\beta 2^{-/-}$and control neurons, which we refer to as response homeostasis. We also find that this inverse relationship persists after lesioning the ipsilateral visual cortex, suggesting that input from V1 is not necessary for maintaining response homeostasis. Furthermore, size-tuning experiments confirm that the amount of retinal area feeding into any given SC cell is much larger in $\beta 2^{-/-}$animals than in controls. Our in vitro analysis shows that response homeostasis is instead associated with the modulation of the number and strength of retinal inputs. In young adults aged P21-P25, $\beta 2^{-1-}$ SC neurons sample a similar number of equal strength retinal inputs from a larger retinal area relative to controls. Interestingly, homeostasis is also maintained earlier in development at P6-P7 in $\beta 2^{-/-}$SC neurons, but via a different mechanism. At this age, $\beta 2^{-/-}$SC neurons sample a larger number of weaker strength retinal inputs than controls.

\section{Model of activity-dependent synapse development and homeostasis}

There are a range of mechanisms that could reasonably account for the difference in the number and strength of retinal inputs that $\beta 2^{-1-}$ SC neurons sample over development. For instance, synaptic maturation could be delayed in $\beta 2^{-1-}$ neurons because of differences in the distribution of activity across the population of retinal ganglion cell neurons in $\beta 2^{-/-}$mice (McLaughlin et al., 2003 ) or the absence of a trophic signal mediated by $\beta 2$ receptors. However, we propose a model that takes into account the instructive information encoded in retinal wave activity (Fig. 7). Initially, a large number of weak retinal inputs use molecular cues to invade the SC in a diffuse manner (McLaughlin and O'Leary, 2005). As slow and infrequent spontaneous waves of activity traverse the retina during early postnatal development, distant retinal inputs with uncorrelated activity are selectively eliminated based on Hebb-type synaptic learning rules at retinocollicular synapses (Fig. 7A, left). Concurrently, neighboring correlated inputs are strengthened and stabilized, leading to a mature, refined map (Constantine-Paton and Cline, 1998; Butts, 2002). In $\beta 2^{-/-}$ animals that lack correlated retinal waves during the first week, the activity-dependent signal necessary for strengthening and pruning retinocollicular synapses is lost, and SC neurons continue to sample a large number of weak retinal inputs relative to control animals with normal wave activity (Fig. 7A, right). After correlated retinal waves are restored during the second week in $\beta 2^{-1-}$ mice, an instructive signal is once again able to guide the elimination of uncorrelated inputs and the strengthening of correlated inputs (Fig. $7 B$, right). This leads $\beta 2^{-/-}$SC neurons to sample a similar number of equally strengthened synapses relative to control mice, but from a larger retinal area. 
A

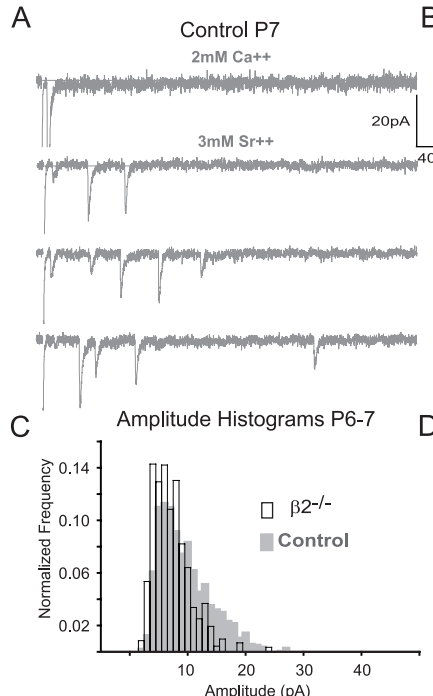

E

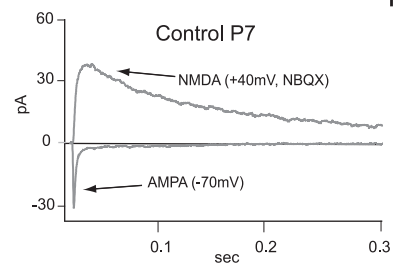

$\mathrm{F}$
B

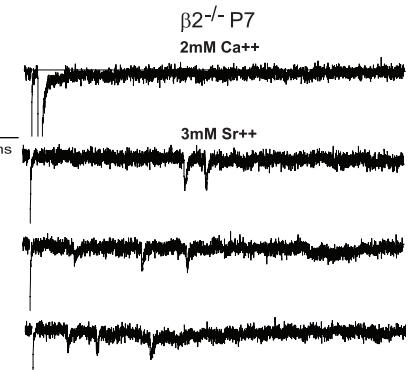

D
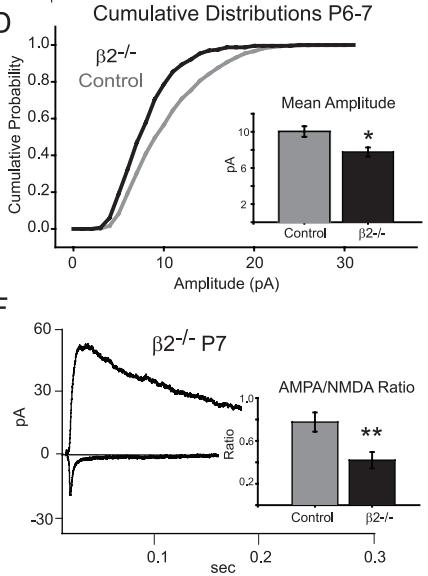

Figure 5. $\quad B 2^{-/-}$neurons have weaker retinocollicular synapses than controls at P6 $-\mathrm{P} 7 . A$, $B$, Example strontium-evoked AMPA miniature experiments for a control (gray) and $\beta 2^{-1-}$ (black) cell at P7, as described in Figure 3, $A$ and $B$. The bottom traces show examples of three sweeps evoked after replacing extracellular $\mathrm{Ca}^{2+}$ with $\mathrm{Sr}^{2+}$. Note the absence of large amplitude events in $\beta 2^{-/-}$examples. $C$, Mean amplitude histograms of all evoked AMPA miniature events in P6-P7 control (gray-filled, $n=8$ ) and $\beta 2^{-/-}$(open bars, $n=5$ ) cells, showing many more large-amplitude AMPA miniature events in control than in $\beta 2^{-/-}$neurons. $\boldsymbol{D}$, The mean cumulative probability distribution for $\beta 2^{-/-}$neurons (black) was shifted toward lower amplitudes compared with the control neurons (gray). Inset, The mean amplitude of the AMPA miniature evoked events is smaller in the $\beta 2^{-1-}$ mice than in control mice $\left({ }^{*} p<0.05\right) . \boldsymbol{E}, \boldsymbol{F}$, Example AMPA/NMDA ratio experiments for a P7 control (gray) and P7 $\beta 2^{-/-}$(black) neuron. Inset, Summary of mean AMPA/NMDA ratios. The values for $\beta 2^{-/-}$neurons are significantly smaller than controls (control in gray, $n=9 ; \beta 2^{-1-}$ in black, $n=8 ;{ }^{* *} p<0.01$ ).

\section{Competing instructive signals may limit}

\section{topographic refinement}

Why do SC neurons in mature $\beta 2^{-/-}$mice continue to sample inputs from a larger retinal area than control mice, despite the onset of correlated glutamate-mediated waves in the retina? We envision two possibilities. First, with the onset of glutamatemediated waves in $\beta 2^{-/-}$mice, the critical period for large scale retinocollicular axon arbor refinement may have passed, allowing only local changes (Muir-Robinson et al., 2002; McLaughlin et al., 2003). Alternatively, the nature of the instructive signal provided by glutamate-mediated retinal waves might not be optimized for mapping topography. These second week waves are faster and more frequent than $\beta 2$-nAChR-mediated waves (Demas et al., 2003, 2006) (Fig. 7B), which would directly result in an increase in the temporal correlations between distant RGCs and, therefore, less precise topographic refinement.

It is also possible that glutamate-mediated waves in the second week contain signals that are instructive for features other than topography. For example, the onset of glutamate waves leads to ON and OFF RGCs acquiring distinct spontaneous firing properties (Myhr et al., 2001). These distinct firing properties are thought to cause the segregation of ON and OFF laminas in the ferret LGN (Lee et al., 2002). In control SC neurons, nicotinic

A

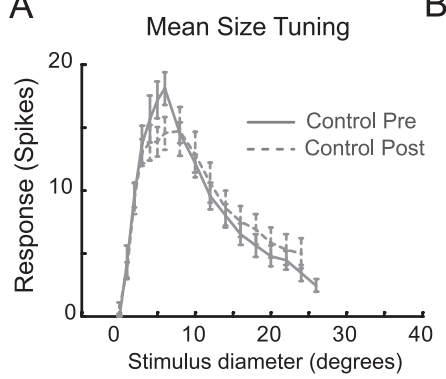

B

C

RF Area

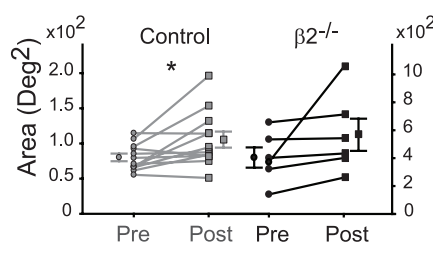

$E$

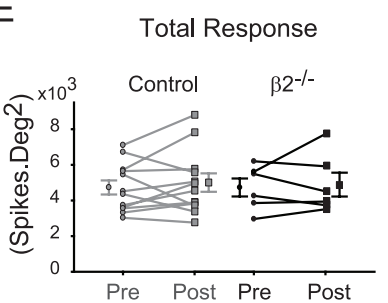

$\mathrm{F}$
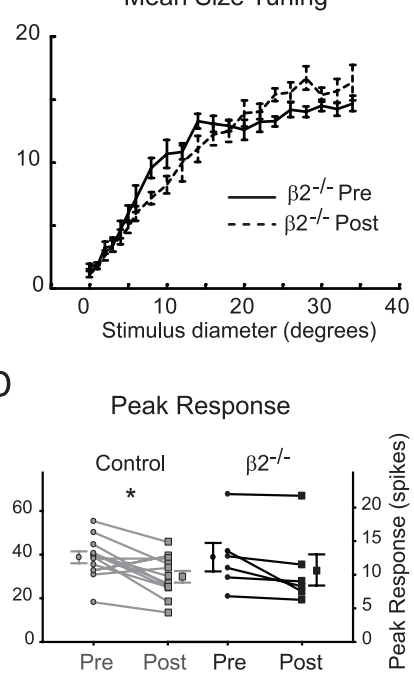

D

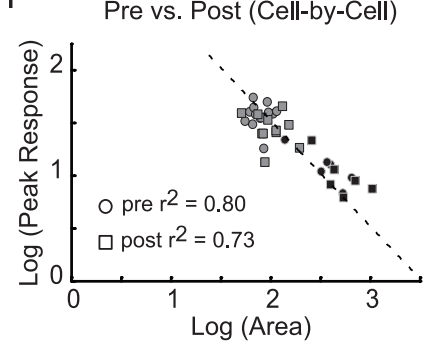

Figure 6. Visual cortex is not required for maintaining homeostasis in the superior colliculus. $\boldsymbol{A}$, Size-tuning curves (average of $n=12$ ) in control mice. Visual stimuli consisted of discs of light of varying diameter positioned at the $\mathrm{SC}$ neuron receptive field center. Size-tuning curves for the same isolated neuron (response as a function of stimulus size) were determined before (gray solid line) and after (gray dashed line) lesioning the ipsilateral visual cortex. The curve peaks early and drops off rapidly both prelesion and postlesion. $B$, Neurons (average of $n=6$ ) in $\beta 2^{-1-}$ mice have altered size-tuning curves that monotonically increase to their peak at a much larger diameter (black solid line), consistent with their large RF size. This is true postlesion as well (black dashed line). C, Comparison of RF area prelesion and postlesion. There is a small, but statistically significant increase in RF area in control neurons (prelesion, gray circles; postlesion, gray squares; paired t test, ${ }^{*} p<0.05$ ), whereas in $\beta 2^{-1-}$ mice (prelesion, black circles; postlesion, black squares), there is a similar but nonsignificant trend (paired $t$ test, $p=0.18$ ). $\boldsymbol{D}$, Comparison of peak response prelesion and postlesion reveals the opposite trend. Across the population of control and $\beta 2^{-/-}$mice, there is a significant decrease in peak response postlesion ( $p<0.05$, two-way ANOVA). This difference is significant in the control mice (paired $t$ test, $\left.{ }^{*} p<0.01\right)$ with a similar trend in $\beta 2^{-/-}$mice that does not reach statistical significance $(p=0.08)$. $E$, There is no difference in the total response prelesion and postlesion across the population of control and $\beta 2^{-/-}$mice ( $p=0.7$, two-way ANOVA), or in each group by themselves (control, $p=0.43 ; \beta 2^{-\prime-}, p=0.73$ ). $\boldsymbol{F}$, A cell-by-cell analysis of the relationship between peak response and area in the log domain shows that the population data are well fit by a line with slope -1 (dashed line), both prelesion and postlesion (prelesion, $r^{2}=0.80$; postlesion, $r^{2}=0.73$ ), demonstrating that response homeostasis in the superior colliculus persists after removing the visual cortex.

waves result in the strengthening and pruning of retinocollicular synapses based on topographic instructive signals, which prevents the subsequent emergence of $\mathrm{ON}$ and OFF selectivity in SC neurons. This results in control SC neurons that are predominantly $\mathrm{ON}-\mathrm{OFF}$ responsive (supplemental Fig. $3 A$, available at www.jneurosci.org as supplemental material). In contrast, $\beta 2^{-/-}$ retinocollicular synapses remain immature after the first week, and subsequently acquire purely $\mathrm{ON}$ or purely OFF selectivity in their responses (supplemental Fig. 3B, available at www. jneurosci.org as supplemental material) at the expense of topography. In support of this hypothesis of competing instructive 


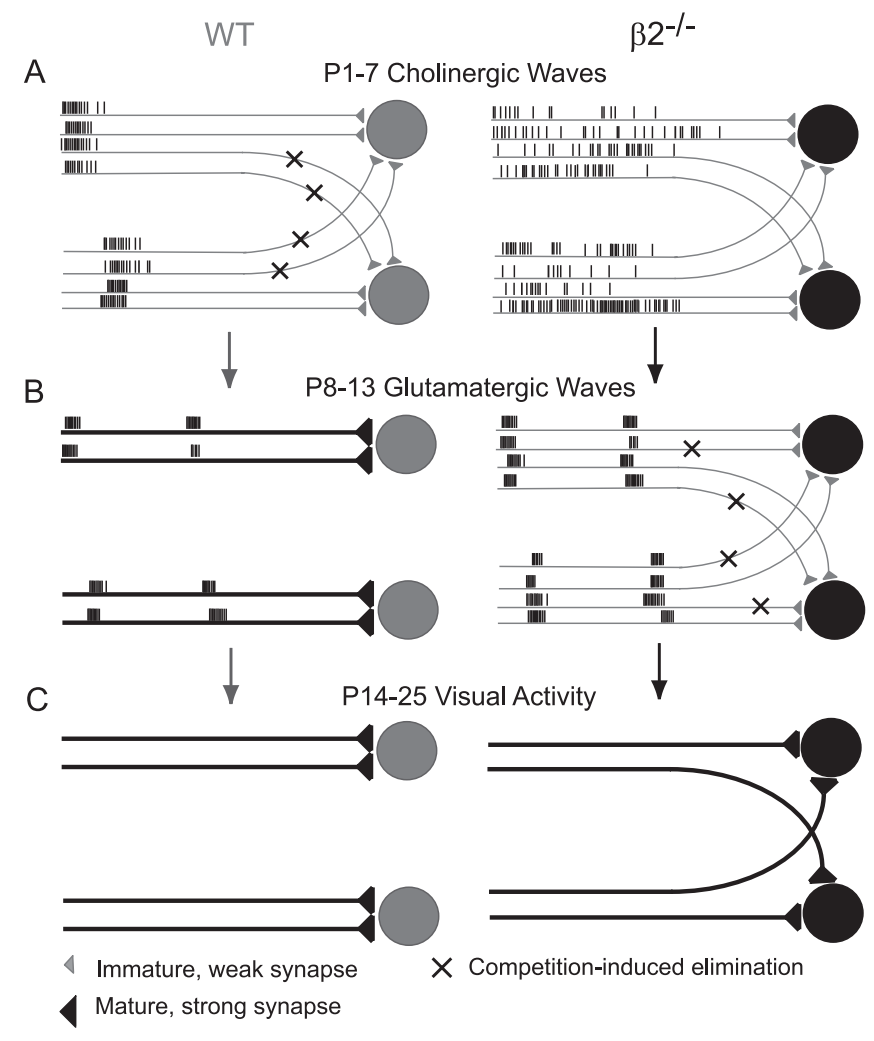

Figure 7. Model of activity-dependent development and homeostasis of retinocollicular synapses. $\boldsymbol{A}$, Early in development, coarse targeting of RGCs consists of numerous topographically inappropriate connections with weak, immature synapses. In WT animals, correlated $n A C h R$-mediated retinal waves propagate during the first postnatal week, resulting in the elimination of uncorrelated inputs ( $\boldsymbol{A}$, left, designated by " $\left.x^{\prime \prime}\right)$ and the selective strengthening of appropriate inputs. $\boldsymbol{B}$, This leads to map refinement by $P 8$ (left). In the absence of correlated waves in $\beta 2^{-/-}$mice $(\boldsymbol{A}$, right), strengthening and pruning fails to occur during the first week ( $\boldsymbol{B}$, right). The onset of correlated, glutamate-mediated waves during the second week allows for strengthening and pruning to occur in $\beta 2^{-/-}$mice ( $\boldsymbol{B}$, right). The distinct statistics of glutamate waves, however, prevent precise topographic refinement (for explanation, see Discussion). $C$, This leads to the preservation of a similar number of equal-strength retinal inputs in $\beta 2^{-1-}$ mice relative to controls but from a larger retinal area.

signals, there is a tendency for $\mathrm{ON}$ and OFF cells to cluster in groups separately in the LGN of $\beta 2^{-/-}$mice, whereas in WT mice they do not (Grubb et al., 2003).

\section{Evidence for synaptic maturation, homeostasis, and pruning during retinotectal map formation}

In the frog retinotectal system, an NMDA receptor-dependent LTP-like process acts via calcium-calmodulin-dependent protein kinase II (CaMKII) to produce a developmental increase in AMPA/NMDA ratios at retinotectal synapses (Wu et al., 1996; Cline, 2001). Overexpression of CaMKII in tectal cells stabilizes RGC axons and slows tectal cell dendrite growth (Zou and Cline, 1996; Wu and Cline, 1998), supporting the hypothesis that in the absence of a stabilization signal, axons and dendrites remain dynamic and continue to form immature synapses. In the rodent SC as well, chronic blockade of NMDAR activity results in a greater density of RGC synapses after the first postnatal week and chronic NMDA treatment reduces the number of retinocollicular synapses formed, offering additional proof that patterned activity leads to the selective elimination and refinement of retinal inputs through postsynaptic learning rules (Shi et al., 2001; Colonnese and Constantine-Paton, 2006).
The process of strengthening and pruning of retinal inputs has been observed in several areas of the developing visual system (Katz and Shatz, 1996). Over the first 3 postnatal weeks in the mouse LGN, retinal inputs are pruned and the AMPA/NMDA ratios and AMPA miniature amplitudes of the remaining retinal inputs increase (Chen and Regehr, 2000). In the frog retinotectal system, excitatory visual receptive fields are initially large and single-fiber retinal inputs are small. Over the course of development, RF areas decrease and the remaining retinal inputs are strengthened (Tao and Poo, 2005). Like our results, these findings suggest that homeostatic mechanisms act through developmental learning rules to shape the functional connectivity of mature visual systems.

It is interesting to note that the developmental pruning of retinal inputs onto mouse LGN neurons results in the survival of only one or two RGCs per neuron (Chen and Regehr, 2000), in contrast to our observation of $4-5$ in the SC. This difference may account for why RFs are not larger in the LGN of $\beta 2^{-/-}$mice (Grubb et al., 2003; Grubb and Thompson, 2004), presumably because many LGN neurons receive input from only one RGC, regardless of retinal location. In the SC, in contrast, more inputs can be spread out over a larger retinal area, resulting in larger RF areas when these inputs are not refined by retinal waves. It is also interesting that, unlike in the mouse LGN (Chen and Regehr, 2000), we do not observe additional pruning of retinal inputs onto SC cells after P6-P7. The apparent difference in the developmental time course and end-point of RGC axon pruning between the SC and LGN may reflect differences in how their outputs guide behavior. SC neurons generate a population code for saccade generation, and therefore may need to integrate a higher number of retinal inputs (Sparks, 2002). In contrast, lower convergence in the LGN may be required for the faithful transmission of information from the retina to the cortex. It is also possible that methodological differences in the retinocollicular and retinogeniculate slice preparations result in different estimates of developmental pruning. Because we cannot guarantee that a similar fraction of retinal inputs are contained within our slice preparation across ages, we base our conclusions on the differences between genotypes at each age.

\section{Alternative cellular and network mechanisms for response homeostasis}

In addition to synaptic learning rules, alternative mechanisms could maintain response homeostasis in the SC. Cell-autonomous processes could regulate the absolute level of total synaptic input, as is observed with synaptic scaling in response to changes in global activity levels (Turrigiano et al., 1998; Desai et al., 2002; Turrigiano and Nelson, 2004). The retinal wave manipulation in $\beta 2^{-1-}$ mice, however, specifically alters the pattern of afferent activity, without changing global levels of activity. Despite this experimental difference, synaptic scaling mechanisms might still promote competition among retinal inputs and maintain response homeostasis in vivo (Turrigiano, 1999). Under this paradigm, the strengthening of a few coactive synapses will cause a rise in postsynaptic firing rates, and scaling mechanisms would then initiate a decrease in strength of all the synapses onto that neuron. Assuming that a certain level of depression will lead to synapse elimination (Fitzsimonds and Poo, 1998), scaling mechanisms would therefore result in the removal of the weakest retinal inputs in response to the selective strengthening of other retinal inputs.

Cell-autonomous mechanisms for maintaining intrinsic neu- 
ronal excitability, such as modulation of voltage-gated ion channels, could also regulate response homeostasis (Davis and Bezprozvanny, 2001; Burrone and Murthy, 2003). An additional possibility is that intracollicular circuitry downstream of retinal activity is used to compensate for changes in total synaptic input. Despite these alternatives, we have demonstrated that adjustments in the number and strength of retinal inputs during development are sufficient to explain the observed response homeostasis in vivo.

During vertebrate CNS development, Hebbian learning rules are thought to mediate the activity-dependent refinement of neural circuits. However, these learning rules are inherently unstable, and would result in runaway strengthening or depression in the absence of homeostasis (Turrigiano, 1999; Turrigiano and Nelson, 2004). A form of response homeostasis similar to our findings occurs at the Drosophila neuromuscular junction, where there is precise regulation of the number and strength of motor neuron synapses onto muscle fibers in the face of changing activity patterns (Schuster et al., 1996; Davis and Goodman, 1998a,b; Davis et al., 1998). Together with our data, these studies suggest that homeostatic mechanisms act through activitydependent learning rules in a diverse range of neural systems to permit the fine-scale refinement of functional connectivity during development while preserving output response within an effective range.

\section{References}

Bansal A, Singer JH, Hwang BJ, Xu W, Beaudet A, Feller MB (2000) Mice lacking specific nicotinic acetylcholine receptor subunits exhibit dramatically altered spontaneous activity patterns and reveal a limited role for retinal waves in forming $\mathrm{ON}$ and OFF circuits in the inner retina. J Neurosci 20:7672-7681.

Berman N, Cynader M (1976) Early versus late visual cortex lesions: effects on receptive fields in cat superior colliculus. Exp Brain Res 25:131-137.

Burrone J, Murthy VN (2003) Synaptic gain control and homeostasis. Curr Opin Neurobiol 13:560-567.

Butts DA (2002) Retinal waves: implications for synaptic learning rules during development. Neuroscientist 8:243-253.

Chandrasekaran AR, Plas DT, Gonzalez E, Crair MC (2005) Evidence for an instructive role of retinal activity in retinotopic map refinement in the superior colliculus of the mouse. J Neurosci 25:6929-6938.

Chen C, Regehr WG (2000) Developmental remodeling of the retinogeniculate synapse. Neuron 28:955-966.

Cline HT (2001) Dendritic arbor development and synaptogenesis. Curr Opin Neurobiol 11:118-126.

Colonnese MT, Constantine-Paton M (2006) Developmental period for $\mathrm{N}$-methyl-D-aspartate (NMDA) receptor-dependent synapse elimination correlated with visuotopic map refinement. J Comp Neurol 494:738-751.

Constantine-Paton M, Cline HT (1998) LTP and activity-dependent synaptogenesis: the more alike they are, the more different they become. Curr Opin Neurobiol 8:139-148.

Constantine-Paton M, Cline HT, Debski E (1990) Patterned activity, synaptic convergence, and the NMDA receptor in developing visual pathways. Annu Rev Neurosci 13:129-154.

Davis GW, Bezprozvanny I (2001) Maintaining the stability of neural function: a homeostatic hypothesis. Annu Rev Physiol 63:847-869.

Davis GW, Goodman CS (1998a) Genetic analysis of synaptic development and plasticity: homeostatic regulation of synaptic efficacy. Curr Opin Neurobiol 8:149-156.

Davis GW, Goodman CS (1998b) Synapse-specific control of synaptic efficacy at the terminals of a single neuron. Nature 392:82-86.

Davis GW, DiAntonio A, Petersen SA, Goodman CS (1998) Postsynaptic PKA controls quantal size and reveals a retrograde signal that regulates presynaptic transmitter release in Drosophila. Neuron 20:305-315.

Demas J, Eglen SJ, Wong RO (2003) Developmental loss of synchronous spontaneous activity in the mouse retina is independent of visual experience. J Neurosci 23:2851-2860.

Demas J, Sagdullaev BT, Green E, Jaubert-Miazza L, McCall MA, Gregg RG, Wong RO, Guido W (2006) Failure to maintain eye-specific segregation in nob, a mutant with abnormally patterned retinal activity. Neuron 50:247-259.

Desai NS, Cudmore RH, Nelson SB, Turrigiano GG (2002) Critical periods for experience-dependent synaptic scaling in visual cortex. Nat Neurosci 5:783-789.

Fitzsimonds RM, Poo MM (1998) Retrograde signaling in the development and modification of synapses. Physiol Rev 78:143-170.

Goda Y, Stevens CF (1994) Two components of transmitter release at a central synapse. Proc Natl Acad Sci USA 91:12942-12946.

Grubb MS, Thompson ID (2004) Visual response properties in the dorsal lateral geniculate nucleus of mice lacking the $\beta 2$ subunit of the nicotinic acetylcholine receptor. J Neurosci 24:8459-8469.

Grubb MS, Rossi FM, Changeux JP, Thompson ID (2003) Abnormal functional organization in the dorsal lateral geniculate nucleus of mice lacking the $\beta 2$ subunit of the nicotinic acetylcholine receptor. Neuron 40:1161-1172.

Kalatsky VA, Stryker MP (2003) New paradigm for optical imaging: temporally encoded maps of intrinsic signal. Neuron 38:529-545.

Katz LC, Shatz CJ (1996) Synaptic activity and the construction of cortical circuits. Science 274:1133-1138.

Lee CW, Eglen SJ, Wong RO (2002) Segregation of ON and OFF retinogeniculate connectivity directed by patterned spontaneous activity. J Neurophysiol 88:2311-2321.

Lu HC, Butts DA, Kaeser PS, She WC, Janz R, Crair MC (2006) Role of efficient neurotransmitter release in barrel map development. J Neurosci 26:2692-2703.

Malinow R, Malenka RC (2002) AMPA receptor trafficking and synaptic plasticity. Annu Rev Neurosci 25:103-126.

McLaughlin T, O'Leary DD (2005) Molecular gradients and development of retinotopic maps. Annu Rev Neurosci 28:327-355.

McLaughlin T, Torborg CL, Feller MB, O'Leary DD (2003) Retinotopic map refinement requires spontaneous retinal waves during a brief critical period of development. Neuron 40:1147-1160.

Meister M, Wong RO, Baylor DA, Shatz CJ (1991) Synchronous bursts of action potentials in ganglion cells of the developing mammalian retina. Science 252:939-943.

Mrsic-Flogel TD, Hofer SB, Creutzfeldt C, Cloez-Tayarani I, Changeux JP, Bonhoeffer T, Hubener M (2005) Altered map of visual space in the superior colliculus of mice lacking early retinal waves. J Neurosci 25:6921-6928.

Muir-Robinson G, Hwang BJ, Feller MB (2002) Retinogeniculate axons undergo eye-specific segregation in the absence of eye-specific layers. J Neurosci 22:5259-5264.

Myhr KL, Lukasiewicz PD, Wong RO (2001) Mechanisms underlying developmental changes in the firing patterns of ON and OFF retinal ganglion cells during refinement of their central projections. J Neurosci 21:8664-8671.

Rhoades RW, Chalupa LM (1978a) Functional and anatomical consequences of neonatal visual cortical damage in superior colliculus of the golden hamster. J Neurophysiol 41:1466-1494.

Rhoades RW, Chalupa LM (1978b) Effects of neonatal cortical lesions upon directional selectivity in the superior colliculus of the golden hamster. Brain Res 147:188-193.

Schuster CM, Davis GW, Fetter RD, Goodman CS (1996) Genetic dissection of structural and functional components of synaptic plasticity. I. Fasciclin II controls synaptic stabilization and growth. Neuron 17:641-654.

Shi J, Aamodt SM, Townsend M, Constantine-Paton M (2001) Developmental depression of glutamate neurotransmission by chronic low-level activation of NMDA receptors. J Neurosci 21:6233-6244.

Sparks DL (2002) The brainstem control of saccadic eye movements. Nat Rev Neurosci 3:952-964.

Tao HW, Poo MM (2005) Activity-dependent matching of excitatory and inhibitory inputs during refinement of visual receptive fields. Neuron 45:829-836.

Tavazoie SF, Reid RC (2000) Diverse receptive fields in the lateral geniculate nucleus during thalamocortical development. Nat Neurosci $3: 608-616$. 
Torborg CL, Feller MB (2005) Spontaneous patterned retinal activity and the refinement of retinal projections. Prog Neurobiol 76:213-235.

Turrigiano GG (1999) Homeostatic plasticity in neuronal networks: the more things change, the more they stay the same. Trends Neurosci 22:221-227.

Turrigiano GG, Nelson SB (2004) Homeostatic plasticity in the developing nervous system. Nat Rev Neurosci 5:97-107.

Turrigiano GG, Leslie KR, Desai NS, Rutherford LC, Nelson SB (1998) Activity-dependent scaling of quantal amplitude in neocortical neurons. Nature 391:892-896.

Wu G, Malinow R, Cline HT (1996) Maturation of a central glutamatergic synapse. Science 274:972-976.
Wu GY, Cline HT (1998) Stabilization of dendritic arbor structure in vivo by CaMKII. Science 279:222-226.

Xu-Friedman MA, RegehrWG (1999) Presynaptic strontium dynamics and synaptic transmission. Biophys J 76:2029-2042.

Xu W, Orr-Urtreger A, Nigro F, Gelber S, Sutcliffe CB, Armstrong D, Patrick JW, Role LW, Beaudet AL, De Biasi M (1999) Multiorgan autonomic dysfunction in mice lacking the $\beta 2$ and the $\beta 4$ subunits of neuronal nicotinic acetylcholine receptors. J Neurosci 19:9298-9305.

Zhang LI, Poo MM (2001) Electrical activity and development of neural circuits. Nat Neurosci [Suppl] 4:1207-1214.

Zou DJ, Cline HT (1996) Control of retinotectal axon arbor growth by postsynaptic CaMKII. Prog Brain Res 108:303-312. 